\title{
The Instrumental Phase of the Voice Program at the Utrecht School of Acting
}

\author{
Els Schrama \\ School of Acting, Utrecht, The Netherlands
}

Pedagogy in Utrecht focuses on the energy of gesture, inner movement, dynamics of posture, spatial movement and emotional expression. Words catch the ear. Movement is text for the eye.

Lex Berger, 2002

\section{Key Words}

Breath $\cdot$ Resonance $\cdot$ Articulation $\cdot$ Imagination

\begin{abstract}
What skills does a performer need in order to be able to say their lines on stage? What is the input of an actor to be audible and have a lively voice filled with imagination? To train the professional performer, we need to know the purpose and the way to arrive there.
\end{abstract}

Copyright $\odot 2008$ S. Karger AG, Basel

\section{Introduction}

The Utrecht School of Acting considers it a challenge to link the performer's physical achievements to improvements in voice and line recital. Several disciplines teach awareness and training of the body. The movement, performance, and voice teachers as well as the aikido teacher all play a part in the physical development of the performer. Each teacher has his or her own perspective but together they serve a higher goal: to ensure that the future performer develops an acute physical awareness.

A voice teacher can build on a properly trained body and well-developed physical awareness. Voice and move-

\section{KARGER}

Fax +41613061234 E-Mail karger@karger.ch www.karger.com
(C) 2008 S. Karger AG, Base

1021-7762/08/0606-0291\$24.50/0

Accessible online at:

www.karger.com/fpl ment are inseparable. In the instrumental phase of education the question is, which path will a starting performer take in the search for an individual voice, articulation and resonance as the audible culmination of an inner process?

\section{Speech Techniques}

What skills does a performer need in order to be able to say their lines on stage: to be audible, intelligible and tuned to the role?

Speech is a complex physical process, the combined action of a series of vocal patterns acquired in childhood years. A performer wanting to develop his or her voice seeks a way to access his/her body in order to create new impulses, to find a new physical balance and to break through old patterns.

A new student must therefore start exercising in order to be able to effect a change. Breathing and articulation are therefore a good starting point for voice education.

This text was presented in a lecture at the PEVOC7 in Groningen in August 2007.

\section{Els Schrama}

Engelsmanplaat 18

NL-3524 AZ Utrecht (The Netherlands)

Tel. +31 610083501

E-Mail elsch@xs4all.nl 
First of all, when learning breathing, the student will focus on finding the balance between tension and relaxation. The performer should be able to relax and contract his or her musculature of the torso in a way that creates optimal space for breathing movements. I will be using the term 'vertical breathing' for breathing while at rest, when breathing is deep and relaxed. Breathing whilst talking, however, is anything but relaxed. Diaphragmatic contraction and elasticity are called upon and are together a vital movement, which I call 'horizontal breathing'. This is comparable to a trampoline. The diaphragm acts as a trampoline and has a highly vital quality. Presence, breathing and alertness (having a living presence) can be intensively experienced in this part of the body. Both horizontal and vertical breathing are exercised and the muscles are made supple. The starting performer will gain knowledge of the physical process through experience and exercise. Both types of breathing will become increasingly balanced with training.

When there is more of a balance between tension and relaxation, the importance of standing with both feet flat on the ground and experiencing circulation throughout the entire body will become visible and perceptible. The performer then experiences his or her inner space. All body movements are perceptible.

Secondly, the performer will be trained to optimally use the resonance spaces in his or her body. Chest and falsetto voices are uncovered and developed and the performer learns the possibilities of the larynx. His/her tone of voice will become richer and the performer can pay more attention to getting the sounds out.

Thirdly, the more refined articulation movements in and around the mouth will be the finishing touch for the performer, who will learn to make an auditory distinction between the various sounds and to reshape them using voluntary movements. Each vowel and consonant has its own shape and flow. Most people have speech irregularities, which will be corrected by the teacher. The training consists of learning how to use correct articulation. Correct articulation contributes to proper directional speaking in a large theatre. This directional speech requires being in shape, vitality and habituation.

An untrained performer can lapse into the wrong solutions. Here are two examples: (1) The performer understands that his or her voice could use more volume, and forces the volume using vertical breathing. This performer does not yet know that by strengthening the horizontal space in the body, the volume can be expanded without having to force it. (2) Wanting to articulate better, the performer thinks that heavy lip and tongue movements will produce the desired effect. Often, the space for vowel resonation will disappear in the battle between lip and tongue.

\section{Learning to Listen}

Besides breathing and articulation training, performers are also taught to listen. I do this by introducing two roles: the role of the performer and the role of the audience. The team members will act as audience, learning how to listen and give feedback to a performer. The listener will indicate what does and does not come across and the performer will learn to transform feedback into change. The performer will be trained to listen in large rooms and to use this to correct his or her physical stance. The performer will also learn the difference between his/ her own inner experience and the experience of the audience. In this way, the performer will learn how to use his or her voice as a whole and how to put it to work when reciting lines. Perhaps at the beginning, the performer will regard some ways of speech as exaggerated and insincere but, little by little, will find a new balance in his or her way of speaking.

A listener does not want to hear that a performer is having to work hard. The listener understands the lines and wants to experience the performer's speech as 'natural'. This way of speaking requires constant care, focus and insight and that will not end with the instrumental phase.

These experiences are important in moving towards the next step: integrating lines into acting. Technique alone does not make a performer. Technique is a basic principle by which to create the possibility for reciting lines clearly in a large room using a sonorous voice.

\section{Lines and Voice, the First Developments}

A performer is expected to bring his or her lines to life by means of sound, articulation, controlled breathing and imagination. A performer presents a text written by someone else to an audience. There is a difference between everyday speech and text written for the theatre. Text will become clear and audible using techniques, clearly distinguishing the performer's way of speaking from everyday speech.

But a performer has more means at his or her disposal to bring a text to life. For instance, the use of sentence melody, intervals, accents, rhythm, loudness and voice color. 
In order to investigate which of these a performer uses, I have developed a special series of lessons, which I will now briefly describe. The basic principle is 'a text without dignity' - an instruction manual, for example, rather than a text for the stage.

During the first class, the text will be read neutrally. It is an insignificant text, filled with every routine pattern, both melodic and dull. This text has no place on a stage.

I will then have the performer put dots and commas in strange places, after which the performer will try to read the words using the new punctuation. Students will have to do their utmost to deliver a good speech. There will be strange textual connections and changes in content. They will get confused about the text, but it can still be read, even with the strange punctuation. Performers will inadvertently make changes. They will notice that the text can be read using other melodies and other ideas (imagination). It will turn out that the contents are not important as soon as the performer knows how to put the intention across in their sound, melody and voice. It forever amazes me how performers emerge from behind the text. Their playfulness will be increased and their prejudice towards the text will disappear. It turns out that feelings do not only depend on the words chosen but sometimes even more on the chosen intonation and accents. During the last class, the text will be read normally, as it was during the first.

The performer must concentrate on several levels: the technique, how he/she deals with the text, and use of imagination. It is as if the performer creates space in order to connect themselves to the text and, at that moment, to give meaning to what he/she is saying.

The performer is amazed at the transformation that has taken place. The lines, the various words and the performer all sound different, more conscious and renewed. The text turns out to have an exigency it did not seem to have before. Every word has meaning, every intonation is emotion and the sound moves more freely through the instrument. The text comes to life.

\section{Final Remarks}

By making room for his or her voice, the performer can increase experience and give it more and more color. Their speaking voice is and will remain unique but, through practice, will become a richer and more theatrical voice. After the initial amazement, it boils down to craftsmanship and skill. The performer must remember that voice and articulation require constant care. If the performer becomes blasé, the skill that has been gained will gradually fade; if the performer has to work too hard, the appearance of being 'natural' will be transformed into speech that is too formulated. An occasional, independent listener and a training program during, and perhaps even after, their studies, are not superfluous luxuries for the performer. 